\title{
The role of the public and private health sectors on factors associated with early essential newborn care practices among institutional deliveries in Ghana
}

Maxwell Tii Kumbeni ${ }^{*}$, Paschal Awingura Apanga ${ }^{2}$, Mary-Ann Wepiamo Chanase ${ }^{3}$, John Ndebugri Alem ${ }^{4}$ and Nana Mireku-Gyimah ${ }^{5}$

\begin{abstract}
Background: Early essential newborn care is one of the important interventions developed by the World Health Organization to reduce morbidities and mortalities in neonates. This study investigated the role of the public and private sector health facilities on factors associated with early essential newborn care practices following institutional delivery in Ghana.

Methods: We used data from the 2017/2018 multiple indicator cluster survey for our analysis. A total of 2749 mothers aged 15-49 years were included in the study. Logistic regression analysis was used to assess the factors associated with early essential newborn care in both public and private health sectors.

Results: The prevalence of good early essential newborn care in the public sector health facilities was $26.4 \%$ (95\% Cl: $23.55,29.30)$ whiles that of the private sector health facilities was $19.9 \%$ (95\% Cl: 13.55, 26.30). Mothers who had a Caesarean section in the public sector health facilities had $67 \%$ lower odds of early essential newborn care compared to mothers who had a vaginal delivery [adjusted prevalence odds ratios (aPOR) $=0.33,95 \% \mathrm{Cl}$ : 0.20, 0.53]. Mothers without a health insurance in the public sector health facilities had $26 \%$ lower odds of early essential newborn care compared to mothers with a health insurance (aPOR $=0.74,95 \% \mathrm{Cl}: 0.56,0.97)$. However, these associations were not observed in the private sector health facilities.

Conclusions: The findings suggest that the prevalence of good early essential newborn care in the public sector health facilities was higher than that reported in the private sector health facilities. Child health programs on early essential newborn care needs to be prioritized in the private healthcare sector. The Government of Ghana may also need to increase the coverage of the national health insurance scheme for women in reproductive age.
\end{abstract}

Keywords: Early essential newborn care, Public sector health facilities, Private sector health facilities, Factors, Ghana

\footnotetext{
* Correspondence: tiimax2@gmail.com

${ }^{1}$ Ghana Health Service, Nabdam District Health Directorate, Nangodi, Ghana

Full list of author information is available at the end of the article
}

C C The Author(s). 2021 Open Access This article is licensed under a Creative Commons Attribution 4.0 International License, which permits use, sharing, adaptation, distribution and reproduction in any medium or format, as long as you give appropriate credit to the original author(s) and the source, provide a link to the Creative Commons licence, and indicate if changes were made. The images or other third party material in this article are included in the article's Creative Commons licence, unless indicated otherwise in a credit line to the material. If material is not included in the article's Creative Commons licence and your intended use is not permitted by statutory regulation or exceeds the permitted use, you will need to obtain permission directly from the copyright holder. To view a copy of this licence, visit http://creativecommons.org/licenses/by/4.0/ The Creative Commons Public Domain Dedication waiver (http://creativecommons.org/publicdomain/zero/1.0/) applies to the data made available in this article, unless otherwise stated in a credit line to the data. 


\section{Background}

Globally, neonatal mortality accounts for nearly half of all deaths in children under five years [1]. Newborns in subSaharan Africa (SSA) are ten times more likely to die within the first 28 days of life compared to those born in high income countries [2]. The World Health Organization (WHO) instituted the early essential newborn care (EENC) to reduce neonatal morbidity and mortality. The EENC is an evidence-based intervention that provides quality healthcare to all newborns immediately after birth [3]. The provision of EENC consist of the following: drying of the newborn to reduce hypothermia and stimulate breathing $[4,5]$; skin-to-skin contact upon delivery to provide warmth, promote mother-infant bonding, and early initiation of breastfeeding [5-7]; and early initiation of breastfeeding to promote the intake of colostrum by newborns, establish mother and infant bonding, and also promote exclusive breastfeeding $[8,9]$. Evidence suggest that adherence to protocols of EENC is associated with reduced neonatal and infant morbidity and mortality $[5,6,10-12]$.

Studies have indicated that various factors influence the adherence to EENC practices [7, 13-15]. Demographics such as age and educational level of women have been found to be associated with the practice of EENC [14]. Women aged 35 years or more were less likely to have their babies receive EENC compared to women aged 19 years or less. Longer mother's years of schooling (11-14 years) was associated with EENC compared to shorter years of schooling ( $<7$ years). Compliance with EENC practices has been found to be high among trained midwives compared to nurses [15]. Skilled birth attendants who received any form of training on EENC practices had higher compliance to implementation of EENC compared to those who never had any training $[5,16]$. Alexsandra et al. found that Caesarean section is negatively associated with EENC practices [14]. Health facilities with adequate equipment and staff are associated with high compliance towards the implementation of EENC practices [7, 16]. Vesel et al. in Ghana also reported that the prevalence of EENC practices were higher in regional and district/private hospitals compared to lower level health facilities such as health centers, clinics or maternity homes [13].

The healthcare system in Ghana is structured under three levels; primary, secondary and tertiary levels of healthcare. While community-based health planning and services (CHPS) compounds, maternity homes, clinics, health centers and district hospitals operate under the primary level of healthcare, regional hospitals and teaching hospitals operate under the secondary and tertiary levels of healthcare respectively [17]. Most of the private sector facilities participate at primary and secondary levels whiles the public sector facilities operates at all the levels of healthcare in Ghana [18]. Although the private sector health facilities constitutes one-third of all health facilities in the country [18], they provide half of all health services in Ghana [19]. The private sector health facilities are also noted for high level of quality care and customer satisfaction when compared to public sector facilities [20]. However, the public sector facilities are the main beneficiaries of interventions aimed at promoting newborn care at the neglect of the private sector facilities. Ghana's Ministry of Health and its partners usually focus on training health staff in public sector health facilities on newborn care. In addition, logistics and support aimed at promoting newborn care have mostly been channeled to the public sector facilities [21].

There is dearth of knowledge on the prevalence and factors associated with the practice of EENC following institutional deliveries in Ghana. Moreover, studies have not examined the moderating role of the health sector (i.e. private or public) on factors associated with EENC. Our study sought to investigate the role of public and private sector health facilities on factors associated with EENC practices among institutional deliveries in Ghana.

\section{Methods \\ Study population}

The study population was mothers who delivered in a health facility (i.e. institutional delivery) within the past 2 years. Data were analyzed using the 2017-2018 Multiple Indicator Cluster Survey (MICS) conducted in Ghana. The MICS provides robust household data which is nationally representative [22]. The MICS uses a twostage sampling procedure, which involves the selection of census enumeration areas from each sampling strata whiles systematic random sampling was used to select households from each enumeration area [23].

\section{Primary outcome}

The primary outcome was EENC. EENC was defined as a composite measure using three early essential newborn care practices (early initiation of breastfeeding; skin-toskin contact; and drying and wrapping of the baby). EENC was categorized as "good early essential newborn care" for newborns that received all three early essential newborn care practices, and "poor early essential newborn care" if a neonate received otherwise. In our study, early initiation of breastfeeding occurred if a mother puts her baby to the breast within one hour of birth [24]. Skin-to-skin contact was defined as putting the baby directly on the bare skin of the mother's chest immediately after the birth, while drying and wrapping of the baby was defined as drying/wiping and wrapping of the baby immediately after birth. 


\section{Primary variables of interest}

The primary variables of interest were skilled attendant at birth (doctor, nurse/midwife); mode of delivery (Caesarean section, vaginal delivery); health facility type (hospital, health centre/clinic, other health facilities); and perceived delivery size of baby at birth (larger than average, average, smaller than average). Mothers who perceived the size of their baby at birth was larger than average, and mothers who perceived their baby was of average size were compared to mothers who perceived their babies were smaller than the average size. Other health facilities refer to maternity homes or CHPS compounds. Health facilities in our study were also categorized into public and private sector facilities. Public sector health facilities refer to health facilities that are government owned whiles private sector health facilities are privately own.

\section{Covariates}

The covariates in our study were mother's age (15-24, 25-34, 35-49 years); marital status (married/cohabitation, never married); education (no formal education, primary, secondary, college or higher education); and household wealth quintiles (poorest, poor, middle, rich, richest). Other covariates were categorized as place of residence (rural, urban); and parity $(0-3, \geq 4)$; and having health insurance (yes, no). Parity was defined as number of births (i.e. live and still births) a woman has had, whiles having a health insurance is either public (i.e. national health insurance) or private insurance.

\section{Data analysis}

Descriptive statistics and complex survey multivariable logistic regression models were used to analyze the data. Descriptive statistics were used to characterize our study sample, and to assess the prevalence of good early essential newborn care. We presented the overall prevalence of good early essential newborn care, and also stratified the prevalence by public and private sector facilities using a bar chat.

We assessed the association between the primary variables of interest and primary outcome, while adjusting for covariates. Four separate regression models were conducted. The model one (i.e. univariate model) was an unadjusted model to assess the relationship between all variables (i.e. primary variables and covariates) and our primary outcome. Variables in model one that had a $P$ value $<0.2[25,26]$, or variables that were clinically relevant were included in models two, three, and four. Model two was an adjusted model that assessed the relationship between primary variables of interest and primary outcomes while adjusting for covariates. Models three and four were stratified models of model two that assessed the relationship between the primary variables of interest and outcome among mothers who delivered at facilities in the public and private health sectors respectively. Multicollinearity of the models were assessed using pairwise correlation matrix, variance inflation factor and tolerance, and eigensystem analysis of correlation matrix. Each of the model fitness was assessed using likelihood ratio test. A $P$-value $<0.05$ was considered statistically significant.

The complex survey design of MICS was accounted for in all our analyses by applying sample weights, stratification and clustering to ensure the representativeness of our data. We analyzed the data using SAS version 9.3 (SAS Institute, Cary, NC).

\section{Results}

Our study sample comprised of a total of 2749 mothers who delivered in a health facility within the past two years. The number of mothers who delivered in public and private sector health facilities were 2356 and 393 respectively. Majority of the mothers who delivered in public $(46.9 \%)$ and private $(50.2 \%)$ sector health facilities were aged 25-34 years. While most of mothers in private sector health facilities (63\%) lived in urban area, only $46.5 \%$ of those in the public sector health facilities lived in the urban area. Possession of health insurance was similarly distributed among mothers who delivered in public $(66.3 \%)$ and private $(68.3 \%)$ sector health facilities. Caesarean section delivery was higher in private sector $(20 \%)$ compared to the public sector health facilities $(16 \%)$ [Table 1$]$.

An estimated $25.5 \%$ (95\% CI: 22.90, 28.09) of the newborns received good EENC (i.e. newborns who received drying and wrapping, skin-to-skin contact and early initiation of breastfeeding). The prevalence of drying and wrapping, skin-to-skin and early initiation of breastfeeding were $38.3 \%$, (95 \% CI: 35.80, 40.80), 64.4\% (95\% CI: 61.80, 67.00) and 52.3\% (95\% CI: 49.70, 54.90) respectively (results not shown). The prevalence of newborns who received good EENC in public and private sector facilities were $26.4 \%$ (95\% CI: $23.55,29.30)$ and 19.9 \% (95\% CI: 13.55, 26.30), respectively [Fig. 1].

The multivariable logistic regression revealed that newborns who were delivered by caesarean section received $66 \%$ lower odds of good EENC compared to mothers who had vaginal delivery. Mothers without health insurance had lower odds of good EENC for their newborns compared to mothers who had health insurance [Adjusted prevalence odds ratio (aPOR): 0.72, $95 \%$ CI: 0.56, 0.93]. Among mothers who delivered in public sector health facilities, newborns who were delivered by caesarean section (aPOR $=0.33,95 \% \mathrm{CI}: 0.20,0.53)$, and whose mothers had no health insurance had lower odds of good EENC (aPOR = 0.74, $95 \%$ CI: 0.56, 0.97), compared to newborns who were delivered by vaginal 
Table 1 Characteristics of the study population among health facilities in Ghana $(n=2749)$

\begin{tabular}{|c|c|c|}
\hline Characteristics & Public sector facilities, n (\%) & Private sector facilities, $\mathrm{n}(\%)$ \\
\hline \multicolumn{3}{|l|}{ Age (years) } \\
\hline $15-24$ & $690(29.3)$ & $62(15.8)$ \\
\hline $25-34$ & $1105(46.9)$ & $197(50.2)$ \\
\hline $35-49$ & $561(23.8)$ & $134(34)$ \\
\hline \multicolumn{3}{|l|}{ Marital status } \\
\hline Never married & $417(17.7)$ & $44(11.3)$ \\
\hline Married/cohabitation & $1939(82.3)$ & $349(88.7)$ \\
\hline \multicolumn{3}{|l|}{ Education } \\
\hline No formal education & $476(20.2)$ & $39(10)$ \\
\hline Primary & $466(19.8)$ & $72(18.4)$ \\
\hline Secondary & $1276(54.2)$ & $227(57.8)$ \\
\hline College or higher education & $137(5.8)$ & $54(13.8)$ \\
\hline \multicolumn{3}{|l|}{ Household wealth } \\
\hline Poorest & $436(18.5)$ & $37(9.4)$ \\
\hline Poor & $445(18.9)$ & $53(13.5)$ \\
\hline Middle income & $470(19.9)$ & $54(13.8)$ \\
\hline Rich & $521(22.1)$ & $103(26.1)$ \\
\hline Richest & $483(20.5)$ & $146(37.2)$ \\
\hline \multicolumn{3}{|l|}{ Place of residence } \\
\hline Urban & $1095(46.5)$ & $248(63)$ \\
\hline Rural & $1261(53.5)$ & $145(37)$ \\
\hline \multicolumn{3}{|l|}{ Parity } \\
\hline $0-3$ & $1473(62.5)$ & $216(55)$ \\
\hline$\geq 4$ & $882(37.5)$ & $177(45)$ \\
\hline \multicolumn{3}{|l|}{ Health insurance } \\
\hline Yes & $1562(66.3)$ & $269(68.3)$ \\
\hline No & $793(33.7)$ & $125(31.7)$ \\
\hline \multicolumn{3}{|c|}{ Perceived delivery size of baby } \\
\hline Smaller than Average & $408(17.4)$ & $51(13)$ \\
\hline Average & $836(35.6)$ & $146(37.2)$ \\
\hline Larger than Average & $1103(47)$ & $195(49.8)$ \\
\hline \multicolumn{3}{|l|}{ Mode of delivery } \\
\hline Vaginal delivery & $1978(84)$ & $315(80)$ \\
\hline Cesarean section & $377(16)$ & $78(20)$ \\
\hline \multicolumn{3}{|l|}{ Health facility type } \\
\hline Hospital & $1530(64.9)$ & $292(74.3)$ \\
\hline Health centre/clinic & $740(31.4)$ & $75(19.2)$ \\
\hline Others & $86(3.7)$ & $26(6.6)$ \\
\hline \multicolumn{3}{|l|}{ Skilled attendant } \\
\hline Doctor & $200(8.5)$ & $42(10.8)$ \\
\hline Nurse/Midwife & $2146(91.5)$ & $346(89.2)$ \\
\hline
\end{tabular}




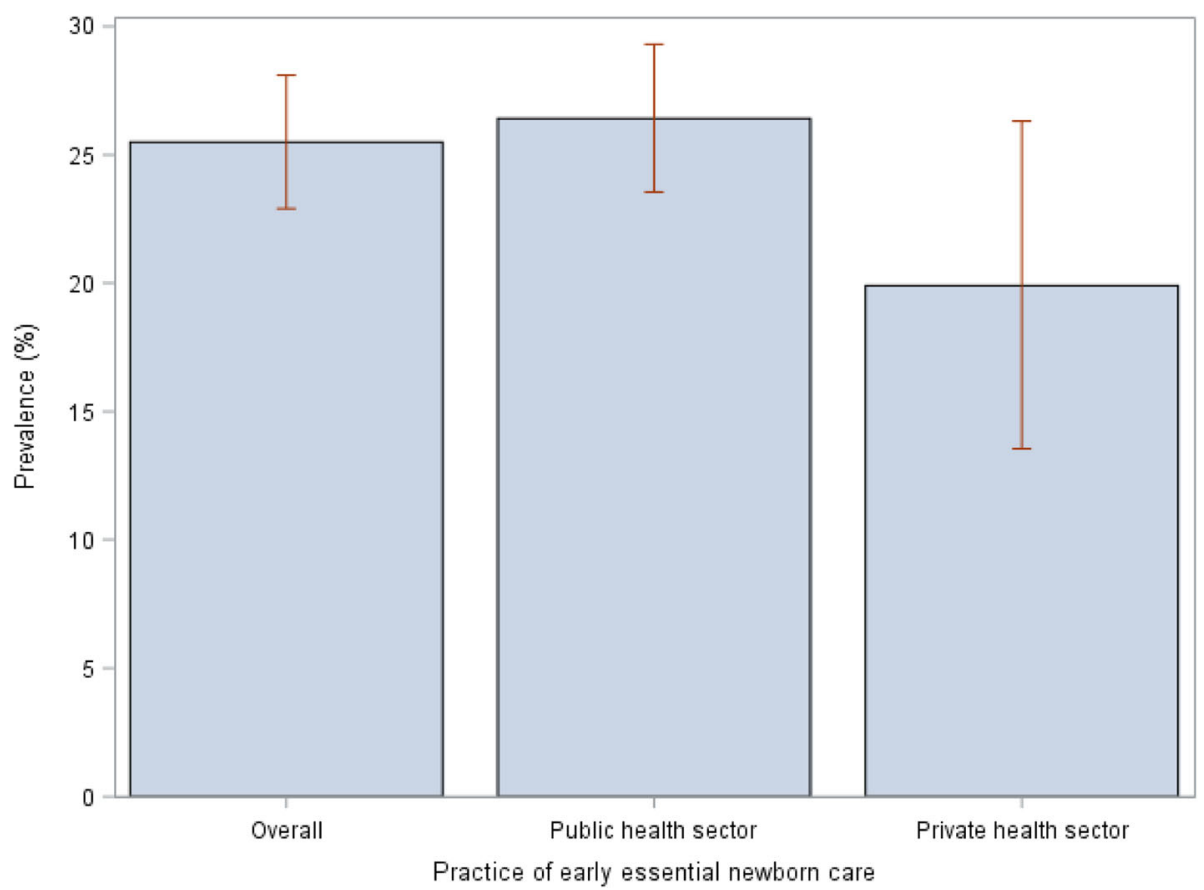

Fig. 1 Practice of early essential newborn care, overall and stratified by health sector

delivery, and whose mothers had a health insurance respectively. Among mothers who delivered in private sector health facilities, none of the variables was associated with the outcome [Table 2].

\section{Discussion}

This study investigated the role of public and private sector health facilities on factors associated with EENC practices following institutional deliveries in Ghana. About one-quarter of babies born in public sector health facilities received good EENC practices whiles an estimated one in five children born in the private sector health facilities received good EENC practices. Caesarean delivery and not having health insurance were associated with lower odds of good EENC practices in the public sector health facilities. However, we did not find any association with the primary outcome in the private sector health facilities.

We found that good EENC practices in the public sector health facilities was higher than those of the private sector health facilities. Several reasons could account for this difference. Firstly, the public sector health facilities has a higher number of skilled health professionals compared to the private sector health facilities [27], and skilled health professionals are more likely to adhere to good EENC practices [28]. In addition, in-service trainings on newborn care from the Ministry of Health and its partners have mostly benefited staff from the public sector health facilities [21]. There is also higher participation in continuous professional development training among staff in the public sector health facilities compared to the private sector health facilities; and knowledge of EENC has been found to be associated with compliance with good EENC practices [5, 16].

Our study also found that Caesarean section was associated with lower odds of good EENC practices in the public sector health facilities. A number of possible reasons might account for this observation. Mothers who delivered by Caesarean section may be uncomfortable adopting to good EENC practices such as early initiation of breastfeeding as they may need some time to recover from anaesthesia $[9,29]$. Furthermore, newborns who were delivered by Caesarean section might suffer birth asphyxia requiring resuscitation that may lead to separation from the mother hence skin to skin and early initiation of breastfeeding will not immediately be possible [9]. Nevertheless, good EENC such as early skin-to-skin contact initiated post Caesarean section has not been found to be associated with any significant risks with regard to neonatal well-being. In this vein, it is essential to commence good EENC practices as early as possible following Caesarean section delivery [30]. Cognizant of the increasing Caesarean section rates globally and in Ghana, it is also imperative that institutional Caesarean section rates be maintained within optimal range so as to improve of neonatal health [31-33]. The results of this study also showed that not having health insurance was associated with lower odds of good EENC practices compared to their peers with a health insurance. Mothers without a health insurance have lower odds of 
Table 2 Factors associated with early essential newborn care during institutional delivery and stratified by public and private sectors health

\begin{tabular}{|c|c|c|c|c|}
\hline Characteristics & $\begin{array}{l}\text { Model } 1 \text { Unadjusted OR } \\
(95 \% \mathrm{Cl})\end{array}$ & $\begin{array}{l}\text { Model } 2 \text { Adjusted OR } \\
(95 \% \mathrm{Cl})\end{array}$ & $\begin{array}{l}\text { Model } 3 \text { Adjusted OR } \\
(95 \% \mathrm{Cl})\end{array}$ & $\begin{array}{l}\text { Model } 4 \text { Adjusted OR } \\
(95 \% \mathrm{Cl})\end{array}$ \\
\hline \multicolumn{5}{|l|}{ Age (years) } \\
\hline $15-24$ & 1 & 1 & 1 & 1 \\
\hline $25-34$ & $0.95(0.71,1.26)$ & $0.97(0.69,1.37)$ & $0.94(0.65,1.35)$ & $1.12(0.30,4.12)$ \\
\hline $35-49$ & $1.02(0.75,1.38)$ & $1.06(0.68,1.66)$ & $1.21(0.76,1.92)$ & $0.43(0.08,2.17)$ \\
\hline \multicolumn{5}{|l|}{ Marital status } \\
\hline Never married & 1 & 1 & 1 & 1 \\
\hline Married/cohabitation & $1.11(0.81,1.51)$ & $1.14(0.79,1.65)$ & $1.24(0.84,1.82)$ & $0.63(0.19,2.12)$ \\
\hline \multicolumn{5}{|l|}{ Education } \\
\hline No formal education & 1 & 1 & 1 & 1 \\
\hline Primary & $0.86(0.56,1.32)$ & $0.96(0.62,1.50)$ & $0.96(0.59,1.55)$ & $0.82(0.17,3.97)$ \\
\hline Secondary & $0.84(0.61,1.16)$ & $0.96(0.66,1.39)$ & $1.04(0.70,1.56)$ & $0.41(0.12,1.47)$ \\
\hline $\begin{array}{l}\text { College or higher } \\
\text { education }\end{array}$ & $0.67(0.39,1.15)$ & $0.88(0.48,1.63)$ & $0.86(0.42,1.76)$ & $0.65(0.16,2.66)$ \\
\hline \multicolumn{5}{|l|}{ Household wealth } \\
\hline Poorest & 1 & 1 & 1 & 1 \\
\hline Poor & $1.06(0.76,1.47)$ & $1.11(0.78,1.57)$ & $1.15(0.79,1.67)$ & $0.75(0.14,4.07)$ \\
\hline Middle income & $0.97(0.66,1.41)$ & $1.04(0.69,1.57)$ & $1.06(0.69,1.63)$ & $0.69(0.11,4.31)$ \\
\hline Rich & $0.75(0.52,1.08)$ & $0.90(0.59,1.37)$ & $0.88(0.56,1.40)$ & $1.41(0.23,8.63)$ \\
\hline Richest & $0.89(0.60,1.33)$ & $1.19(0.70,2.01)$ & $1.13(0.65,1.94)$ & $2.34(0.37,14.67)$ \\
\hline \multicolumn{5}{|l|}{ Place of residence } \\
\hline Urban & 1 & 1 & 1 & 1 \\
\hline Rural & $1.29(0.98,1.70)$ & $1.17(0.86,1.60)$ & $1.14(0.81,1.59)$ & $1.83(0.57,5.83)$ \\
\hline \multicolumn{5}{|l|}{ Parity } \\
\hline $0-3$ & 1 & 1 & 1 & 1 \\
\hline$\geq 4$ & $1.05(0.82,1.36)$ & $0.97(0.69,1.36)$ & $0.98(0.68,1.40)$ & $1.03(0.38,2.75)$ \\
\hline \multicolumn{5}{|l|}{ Health insurance } \\
\hline Yes & 1 & 1 & 1 & 1 \\
\hline No & $0.76(0.60,0.96)$ & $0.72(0.56,0.93) *$ & $0.74(0.56,0.97) *$ & $0.56(0.23,1.41)$ \\
\hline \multicolumn{5}{|c|}{ Perceived delivery size of baby } \\
\hline Smaller than Average & 1 & 1 & 1 & 1 \\
\hline Average & $1.18(0.82,1.68)$ & $1.09(0.77,1.54)$ & $1.09(0.76,1.56)$ & $1.41(0.39,5.06)$ \\
\hline Larger than Average & $1.35(0.96,1.89)$ & $1.26(0.90,1.75)$ & $1.30(0.90,1.86)$ & $1.15(0.36,3.75)$ \\
\hline \multicolumn{5}{|l|}{ Mode of delivery } \\
\hline Vaginal delivery & 1 & 1 & 1 & 1 \\
\hline Caesarean section & $0.32(0.22,0.48)$ & $0.34(0.22,0.52) *$ & $0.33(0.2,0.53) *$ & $0.49(0.15,1.61)$ \\
\hline \multicolumn{5}{|l|}{ Health facility type } \\
\hline Hospital & 1 & 1 & 1 & 1 \\
\hline Health centre/clinic & $1.29(0.98,1.7)$ & $1.06(0.79,1.42)$ & $1.09(0.80,1.46)$ & $0.67(0.19,2.38)$ \\
\hline Others & $1.41(0.69,2.89)$ & $1.30(0.63,2.65)$ & $1.44(0.66,3.15)$ & $0.59(0.10,3.47)$ \\
\hline \multicolumn{5}{|l|}{ Skilled attendant } \\
\hline Doctor & 1 & 1 & 1 & 1 \\
\hline Nurse/Midwife & $2.03(1.28,3.22)$ & $1.31(0.78,2.19)$ & $1.22(0.70,2.13)$ & $3.49(0.57,21.32)$ \\
\hline
\end{tabular}

*P-value less than 0.05 
institutional delivery [34, 35]. Since our study was conducted in health facilities, it is likely that fewer mothers without health insurance participated in the study, and that might account for this finding. The National Health Insurance Scheme (NHIS) in Ghana is very useful as it covers maternal health services including prenatal care, delivery care, postnatal care, and healthcare for child up to 3 months post-delivery. Educating pregnant women on its advantages and encouraging them to take up NHIS will expand coverage, increase institutional delivery, and improve good EENC practices [36].

Although Caesarean section and not having health insurance were observed to be associated with poor EENC practices in the public sector health facilities, same was not observed in the private sector health facilities. Several reasons may possibly explain these findings. With regard to caesarean section, this finding might be due the fact that women who deliver at private health facilities in Ghana are more likely to undergo Caesarean section [37], and that might be the reason for our observation. Furthermore, some private sector health facilities levy clients for user fees irrespective of their health insurance status [38], therefore health insurance status may not play an important role in good EENC practices. The null findings of the association between caesarean section, health insurance and good EENC practices could also be due to random error.

The study had some strengths and limitations. Our study was representative and our findings can therefore be generalized in Ghana. Causal relationships cannot be established due to the cross-sectional design of the study. Most of the variables were self-reported and may be affected by recall bias, however, we expect recall bias to be similar between mothers who reported good EENC and those that did not. Moreover, perceived size of the baby at delivery was self-reported and therefore subject to measurement error as this may not be a reflection of the actual weight of the baby at delivery. However, we also expect measurement error to be similar among neonates who received good EENC and those that did not.

\section{Conclusions}

The prevalence of good EENC practices was higher in the public sector health facilities compared to the private sector health facilities. Caesarean section and no health insurance were associated with lower odds of good EENC practices in the public sector health facilities. However, same was not observed with the private sector health facilities. Efforts to improve good EENC practices in the public sector health facilities should target women who deliver by caesarean section and also those with no health insurance towards the attainment of optimal neonatal health.
Acknowledgements

We are grateful to the UNICEF MICS team for providing us with the data.

Code availability

Available upon request.

Authors' contributions

MTK and PAA conceived the study and analyzed the data. MTK, PAA, MAWC, JNA and NM-G wrote the manuscript. All authors read and approved the final version

Funding

None.

Availability of data and materials

MICS data is publicly available at: https://mics.uniceforg/surveys.

\section{Declarations}

Ethics approval and consent to participate

Not applicable.

Consent for publication

Not applicable.

Competing interests

None declared.

\section{Author details}

'Ghana Health Service, Nabdam District Health Directorate, Nangodi, Ghana. ${ }^{2}$ School of Community Health Sciences, University of Nevada, Reno, USA.

${ }^{3}$ College of Applied Health Science, University of Illinois, Urbana-Champaign, USA. ${ }^{4}$ School of Nursing and Midwifery, University for Development Studies, Tamale, Ghana. ${ }^{5}$ Ghana Health Service, Dansoman Polyclinic,

Dansoman-Accra, Ghana.

Received: 19 February 2021 Accepted: 21 June 2021

Published online: 30 June 2021

\section{References}

1. UNICEF. Levels and Trends in Child Mortality Report 2017. 2017. Available from: https://www.unicef.org/publications/index_101071.html

2. World Health Organization. Newborns: improving survival and well-being. 2020. Available from: https://www.who.int/news-room/fact-sheets/detail/ newborns-reducing-mortality [cited 1 Jan 2021]

3. World Health Organization. Early essential newborn care Clinical practice pocket guide Early essential newborn care Clinical practice pocket guide. Geneva: World Health Organization; 2014. Available from: https://apps.who. int/iris/rest/bitstreams/1246772/retrieve

4. Sobel HL, Silvestre MAA, Mantaring JB V., Oliveros YE, Nyunt $-U$ S. Immediate newborn care practices delay thermoregulation and breastfeeding initiation. Acta Paediatr Int J Paediatr. 2011;100(8):1127-33.

5. Tran HT, Mannava P, Murray JCS, Nguyen PTT, Tuyen LTM, Hoang Anh T, et al. Early Essential Newborn Care Is Associated With Reduced Adverse Neonatal Outcomes in a Tertiary Hospital in Da Nang, Viet Nam: A PrePost- Intervention Study. EClinicalMedicine. 2018;6:51-8.

6. Safari K, Saeed AA, Hasan SS, Moghaddam-Banaem L. The effect of mother and newborn early skin-to-skin contact on initiation of breastfeeding, newborn temperature and duration of third stage of labor. Int Breastfeed J. 2018;13:32.

7. Li Z, Mannava P, Murray JCS, Sobel HL, Jatobatu A, Calibo A, et al. Association between early essential newborn care and breastfeeding outcomes in eight countries in Asia and the Pacific: a cross-sectional observational -study. BMJ Glob Heal. 2020;5:e002581.

8. Bardanzellu F, Fanos V, Reali A. "Omics" in human colostrum and mature milk: looking to old data with new eyes. Nutrients. 2017:9(8):843.

9. Liben ML, Yesuf EM. Determinants of early initiation of breastfeeding in Amibara district, Northeastern Ethiopia: a community based cross-sectional study. Int Breastfeed J. 2016;11:7. 
10. Smith ER, Hurt L, Chowdhury R, Sinha B, Fawzi W, Edmond KM. Delayed breastfeeding initiation and infant survival: a systematic review and metaanalysis. PLoS One. 2017;12(7):e0180722.

11. Moore ER, Anderson GC, Bergman N, Dowswell T. Early skin-to-skin contact for mothers and their healthy newborn infants. Cochrane Database Syst Rev. 2012;

12. Onalo R. Neonatal hypothermia in sub-Saharan Africa: a review. Niger J Clin Pract. 2013;16(2):129-38

13. Vesel L, Manu A, Lohela TJ, Gabrysch S, Okyere E, Asbroek AHA, et al. Quality of newborn care: a health facility assessment in rural Ghana using survey, vignette and surveillance data. BMJ Open. 2013;3:e002326.

14. Alexsandra M, Menezes S, Gurgel R, Duarte S, Bittencourt A, Pacheco VE, et al. Health facility structure and maternal characteristics related to essential newborn care in Brazil: a cross-sectional study. BMJ Open. 2018;8: e021431.

15. Ayenew A, Mahlet A, Mesafint E. Pedric Heal Med Ther. 2020;11:449-58.

16. Horiuchi S, Rattana S, Saysanasongkham B, Kounnavongsa O. Study protocol of a cluster randomized controlled trial to evaluate effectiveness of a system for maintaining high-quality early essential newborn care in Lao PDR. BMC Health Serv Res. 2018;18:489.

17. Dalaba MA, Welaga P, Matsubara C. Cost of delivering health care services at primary health facilities in Ghana. BMC Health Serv Res. 2017;17:742.

18. Wang H, Otoo N, Dsane-Selby L. Ghana National Health Insurance Scheme: Improving Financial Sustainability Based on Expenditure Review. Washington DC: World Bank; 2017.

19. Mart YM, Sealy S, Bitrán RA, Adjei S, Muñoz R. Private Health Sector Assessment in Ghana. Washington DC: World Bank; 2010.

20. Owusu Kwateng K, Lumor R, Acheampong FO. Service quality in public and private hospitals: a comparative study on patient satisfaction. Int J Healthc Manag. 2019;12(4):251-8

21. Chinbuah MA, Taylor M, Serpa M, Mazia G, Cofie PK, Kwarah W, et al. Scaling up Ghana's national newborn care initiative: Integrating "helping babies breathe" (HBB), "essential care for every baby" (ECEB), and newborn "infection prevention" (IP) trainings. BMC Health Serv Res. 2020;20:739.

22. Khan S, Hancioglu A. Multiple Indicator Cluster Surveys: delivering Robust Data on Children. Stud Fam Plann. 2019:50(3):279-86.

23. National Bureau of Statistics (NBS) and UNICEF. Multiple Indicator Cluster Survey Nigeria 2016-17, Survey Findings Report. 2017;

24. Mekonen L, Seifu W, Shiferaw Z. Timely initiation of breastfeeding and associated factors among mothers of infants under 12 months in South Gondar zone, Amhara regional state, Ethiopia; 2013. Int Breastfeed J. 2018; 13:17.

25. Takazono T, Tashiro M, Ota Y, Obata Y, Wakamura T, Miyazaki T, et al. Factor analysis of acute kidney injury in patients administered liposomal amphotericin B in a real-world clinical setting in Japan. Sci Rep. 2020;10 15033.

26. Hirsch P, Tang R, Marzac C, Perrot JY, Fava F, Bernard C, et al. Prognostic impact of high $A B C$ transporter activity in 111 adult acute myeloid leukemia patients with normal cytogenetics when compared to FLT3, NPM1, CEBPA and BAALC. Haematologica. 2012;97(2):241-5.

27. Alhassan RK, Nketiah-Amponsah E, Akazili J, Spieker N, Arhinful DK, Rinke de Wit TF. Efficiency of private and public primary health facilities accredited by the National Health Insurance Authority in Ghana. Cost Eff Resour Alloc. 2015;13:23.

28. Tunçalp, Were WM, Maclennan C, Oladapo OT, Gülmezoglu AM, Bahl R, et al. Quality of care for pregnant women and newborns - The WHO vision. BJOG. 2015;122(8):1045-9.

29. Tilahun G, Degu G, Azale T, Tigabu A. Prevalence and associated factors of timely initiation of breastfeeding among mothers at Debre Berhan town, Ethiopia: A cross-sectional study. Int Breastfeed J. 2016;11:27.

30. Kollmann M, Aldrian L, Scheuchenegger A, Mautner E, Herzog SA, Urlesberger B, et al. Early skin-to-skin contact after cesarean section: a randomized clinical pilot study. PLoS One. 2017;12(2):e0168783.

31. Dankwah E, Zeng W, Feng C, Kirychuk S, Farag M. The social determinants of health facility delivery in Ghana. Reprod Health. 2019;16:101.

32. Paksoy Erbaydar N, Erbaydar T. Relationship between caesarean section and breastfeeding: Evidence from the 2013 Turkey demographic and health survey. BMC Pregnancy Childbirth. 2020;20:55.

33. World Health Organization. WHO Statement on Caesarean Section Rates. 2015; Available from: https://apps.who.int/iris/bitstream/handle/10665/1 61442/WHO_RHR_15.02_eng.pdf?sequence $=1$
34. Twum P, Qi J, Aurelie KK, Xu L. Effectiveness of a free maternal healthcare programme under the National Health Insurance Scheme on skilled care: Evidence from a cross-sectional study in two districts in Ghana. BMJ Open. 2018:8:e022614.

35. Kumbeni MT, Apanga PA. Institutional delivery and associated factors among women in Ghana: findings from a 2017-2018 multiple indicator cluster survey. Int Health. 2021. p. ihab002.

36. Singh K, Osei-Akoto I, Otchere F, Sodzi-Tettey S, Barrington C, Huang C, et al. Ghana's national health insurance scheme and maternal and child health: a mixed methods study. BMC Health Serv Res. 2015;15:108.

37. Yaya S, Uthman OA, Amouzou A, Bishwajit G. Disparities in caesarean section prevalence and determinants across sub-Saharan Africa countries. Glob Heal Res Policy. 2018:3:19.

38. Kodom M, Owusu AY, Kodom PNB. Quality Healthcare Service Assessment under Ghana's National Health Insurance Scheme. J Asian Afr Stud. 2019; 54(4):569-87.

\section{Publisher's Note}

Springer Nature remains neutral with regard to jurisdictional claims in published maps and institutional affiliations.
Ready to submit your research? Choose BMC and benefit from:

- fast, convenient online submission

- thorough peer review by experienced researchers in your field

- rapid publication on acceptance

- support for research data, including large and complex data types

- gold Open Access which fosters wider collaboration and increased citations

- maximum visibility for your research: over $100 \mathrm{M}$ website views per year

At $\mathrm{BMC}$, research is always in progress.

Learn more biomedcentral.com/submissions 